\title{
OBSERVATIONS ON A CASE OF MYOTONIA PARADOXA
}

BY

\author{
JOHN MARSHALL
}

\author{
From the Military Hospital, Wheatley, and Department of Neurology, United Oxford Hospitals
}

Myotonia, the phenomenon of prolonged aftercontraction of a muscle after voluntary effort has ceased, is seen in several conditions of which the commonest are dystrophia myotonica (myotonia atrophica) and myotonia congenita (Thomsen's disease). A rarer manifestation is that designated as paramyotonia in which the myotonia appears only with cold or less usually with heat, while rarest of all is myotonia paradoxa. Whereas in ordinary myotonia the initial movements are most hampered and continued use of the muscle relieves the myotonia, in myotonia paradoxa the myotonia increases with activity until movement may be completely arrested. Maas and Paterson (1950) mention a few authors who have observed this phenomenon. Franceschetti, Klein, and Walthard (1947) quote Curschmann as saying that ordinary myotonia may be found in one group of muscles with myotonia paradoxa in another group in the same patient. The second case described by Franceschetti and others (1947) was one of myotonia in the arms on initial movement, but when the patient came to climb the stairs the myotonia in the legs became progressively worse. The present case was unusual in showing myotonia paradoxa in pure form. Never at any time during daily observation for many weeks was myotonia present on initial movement, nor could the patient recollect such an occurrence at any time in his life. Initial movements were always unencumbered but as movement progressed myotonia developed and increased until he was incapable of further movement.

\section{Case Report}

The patient was a man aged 21 years. His father and mother were both alive and well and had never suffered from any muscular disability. His father went bald as a young man and his paternal grandfather had a cataract. A female second cousin of the patient's mother had suffered from some muscular disease, but its nature was unknown and efforts to trace her failed. He had one sister three years older than himself who was in good health.

The patient could carry his earliest recollection of his disability back to the age of 4 years when it was noticed that he lagged behind his parents when walking because of which they used to chide him. When he started school this disability became more noticeable as he could not keep up with other boys. He was referred to the School Medical Officer and was excused games and physical training. About 13 years of age he became more aware of the nature of his trouble, for after hanging from a horizontal bar by his hands he found that they became weak and powerless while his fingers remained flexed and defied his efforts to extend them voluntarily. This was accompanied by a "knotted feeling" in the bellies of the muscles in the forearm which lasted several minutes, after which the fingers gradually relaxed and the power returned. After leaving school he began work as a draughtsman and, though long-continued drawing would bring on the loss of power in the fingers, he was able to continue his work by means of suitable respites. He was called for National Service and passed through his basic training by being excused drill and parades. Subsequently he continued work as a draughtsman in the Royal Engineers but was never able to do drill, and so he was referred to hospital.

$\mathrm{He}$ described his difficulty well and clearly. Whenever he began to use a muscle or group of muscles the initial movements were free and powerful. With continued exercise, however, there first appeared a dull ache followed quickly by a progressive loss of power in the muscle accompanied by a tight, knotted feeling in its belly. This rapidly led to complete loss of power, the muscle remaining in the shortened position. When he felt the muscle belly at this point it was hard and board-like. After resting a few minutes the muscle gradually relaxed, its belly became soft, and the power returned. If he exercised the muscle more quickly or against a greater resistance the weakness came sooner. By keeping the rate of exercise below a critical level, as for instance in walking slowly, he could avoid the loss of power indefinitely. Rapid walking or walking up steep hills would quickly bring it on. The trouble was worse when he was cold or very hot or when hungry. General bodily fatigue might make the weakness appear more rapidly in a particular group of muscles, but he had not noticed any tendency for it to be worse towards the end of the day. It affected all limb and trunk muscles and also the muscles of mastication and deglutition. He had never noticed any diplopia nor ptosis.

Also he had noticed for several years that occasionally 
when using a muscle it would begin to tighten and weaken as usual and then, though activity was continued, the symptoms subsided and he could then continue to use the muscle indefinitely. This he had named his "second-wind".

He was $5 \mathrm{ft} .9$ in. $(175 \mathrm{~cm}$.) tall and weighed $146 \mathrm{lb}$. (66 kg.). His hair was receding from his forehead and was a little thin over the vertex. The distribution of body hair was normal. The heart, lungs, and abdomen showed no abnormality, and there was no testicular atrophy. In the central nervous system fundi, pupillary reactions, and cranial nerves were all normal. Deep tendon reflexes were active and equal, abdominal reflexes were present, and the plantar responses were flexor. Sensation and coordination were intact.

Muscular development was good, but there was no suggestion of hypertrophy on the one hand nor of atrophy on the other, and the muscles at rest were normal to palpation. There was no disturbance of tone nor was any fasciculation seen. Percussion of the muscles failed to produce a myotonic response. Power, when tested conventionally by using a muscle once or twice against resistance, was normal in all groups of muscles. When a muscle was tested continuously, as for example the biceps brachii by repeatedly flexing the elbow against resistance, the initial movements were powerful, but gradually the power decreased until he would be completely unable to flex the elbow even against gravity. Simultaneously the belly of the biceps was felt to be hard and board-like. This condition persisted from one to three minutes and then gradually passed off as the power returned. In the case of the long flexors of the fingers the hardening of the muscles was accompanied by a shortening which left the fingers in a flexed position.

The serum calcium level was $10.4 \mathrm{mg}$. per $100 \mathrm{ml}$. and serum potassium $17.6 \mathrm{mg}$. per $100 \mathrm{ml}$.

\section{Experiments}

The muscle tests in the following experiments were done as follows.

Quadriceps.-The patient sat on a table with the thighs horizontal and the lower leg hanging vertically downwards over the edge. A loop, carrying a $6 \mathrm{lb}$. weight, was placed over the dorsum of the foot. The patient raised the lower leg to the horizontal by extending the knee and lowered it again at the rate of once every two seconds. The result was scored as the number of times the leg was raised before it failed to reach the horizontal level.

Biceps.-The supinated forearm was laid on the table with a $7 \mathrm{lb}$. weight in the hand. The forearm was raised to the vertical by flexing the elbow and then lowered at a rate of once every two seconds. The result was scored as the number of times the forearm was raised before it failed to reach the vertical.
Index.-The supinated forearm was laid on the table and a loop was placed over the terminal phalanx of the index finger. The loop was attached to a string which passed over a pulley to be attached to a $2 \mathrm{lb}$. weight. The index finger was flexed fully at the proximal interphalangeal joint and then extended. The result was scored as the number of times it was flexed before it failed to reach full flexion.

It should be noted that in every instance the failure to complete the contraction was not due to simple fatigue but to the development of myotonia.

Exporiment 1: Comparison of Patient with Normal Control.- - The power of the patient was compared with a normal control of similar height, weight, and muscular development (Table I), and was found to be greatly impaired by the development of myotonia. This comparison shows clearly how severely the patient was handicapped by his disability.

TABLE I

NUMBER OF MUSCULAR CONTRACTIONS BEFORE FAILURE COMPARED WITH A NORMAL SUBJECT

\begin{tabular}{|c|c|c|c|c|}
\hline \multicolumn{3}{|c|}{ Muscle } & Patient & Control \\
\hline $\begin{array}{l}\text { Right quadriceps } \\
\text { Left quadriceps } \\
\text { Right biceps } \\
\text { Left biceps } \\
\text { Right index } \\
\text { Left index }\end{array}$ & $\begin{array}{l}\cdots \\
\cdots \\
\cdots \\
\cdots \\
\cdots\end{array}$ & $\begin{array}{l}\cdots \\
\cdots \\
\cdots \\
\cdots \\
\cdots\end{array}$ & $\begin{array}{l}51 \\
45 \\
54 \\
75 \\
19 \\
23\end{array}$ & $\begin{array}{r}150 \\
150 \\
150 \\
150 \\
50 \\
50\end{array}$ \\
\hline
\end{tabular}

Experiment 2 : Effect of Hunger and Food.-The patient had no food or drink from 8 p.m. to 9.30 a.m. of the following day. At this time the bloodsugar was measured $(95 \mathrm{mg}$. per $100 \mathrm{ml}$.) and the muscular power was tested. He was then given $100 \mathrm{~g}$. of glucose in water and a large breakfast, then at 11 a.m. the muscular power was re-tested. The blood sugar was then $130 \mathrm{mg}$. per $100 \mathrm{ml}$ The results are recorded in Table II and it appears that depriving the patient of food overnight did not enable the myotonia to be induced more easily. However, after the patient had been given breakfast

\section{TABLE II}

NUMBER OF MUSCULAR CONTRACTIONS REQUIRED TO PRODUCE MYOTONIA BEFORE AND AFTER FOOD

\begin{tabular}{|c|c|c|c|c|}
\hline \multicolumn{3}{|c|}{ Muscle } & Fasting & After Breakfast \\
\hline $\begin{array}{l}\text { Right quadriceps } \\
\text { Left quadriceps } \\
\text { Right biceps } \\
\text { Left biceps } \\
\text { Right index } \\
\text { Left index }\end{array}$ & $\begin{array}{l}\cdots \\
\cdots \\
\cdots \\
\cdots\end{array}$ & $\begin{array}{l}\cdots \\
\cdots \\
\cdots \\
\cdots \\
\cdots\end{array}$ & $\begin{array}{l}56 \\
64 \\
51 \\
56 \\
14 \\
17\end{array}$ & $\begin{array}{c}84 \\
74 \\
152^{*} \\
150^{*} \\
22 \\
21\end{array}$ \\
\hline
\end{tabular}

* In both these instances the patient developed his " second wind" and was still going strongly when stopped at 152 and 150 . 
and the blood sugar had risen from 95 to $130 \mathrm{mg}$. there was a slight improvement in performance.

Experiment 3 : Effect of Repeated Testing.-The results of repeated testing of a muscle were observed by testing "the index" to the point of failure at 5-minute intervals. The results in Table III show that recurrent use of a muscle at short intervals did not aggravate the myotonia, which fact was supported by the clinical observation that the patient was not worse towards the end of the day.

\section{TABLE III}

EFFECT OF REPEATED TESTING ON NUMBER OF MUSCULAR CONTRACTIONS REQUIRED TO PRODUCE MYOTONIA

\begin{tabular}{|c|c|c|c|c|c|}
\hline \multicolumn{3}{|c|}{ Time } & Zero & 5 minutes & 10 minutes \\
\hline $\begin{array}{l}\text { Right index } \\
\text { Left index }\end{array}$ & $\ddot{m}$ & $\ddot{x}$ & $\begin{array}{l}11 \\
12\end{array}$ & $\begin{array}{l}9 \\
8\end{array}$ & $\begin{array}{l}13 \\
13\end{array}$ \\
\hline
\end{tabular}

Experiment 4: Effect of Temperature.-The effects of temperature were observed by immersing the hand and forearm in a bath of water or melting ice at $1^{\circ} \mathrm{C}$., $9^{\circ} \mathrm{C}$., $15^{\circ} \mathrm{C}$, , and $41^{\circ} \mathrm{C}$. for five minutes each. This alteration of temperature as shown in Table IV did not produce any great effect, though the patient had considered his trouble to be somewhat worse in extreme heat or cold. This is in contrast to paramyotonia where the myotonia develops only in the cold.

\section{TABLE IV}

EFFECT OF TEMPERATURE ON NUMBER OF MUSCULAR CONTRACTIONS REQUIRED TO PRODUCE MYOTONIA

\begin{tabular}{lc|c|c|c|c}
\hline \multicolumn{2}{c|}{ Temperature } & $1^{\circ} \mathrm{C}$. & $9^{\circ} \mathrm{C}$. & $15^{\circ} \mathrm{C}$. & $41^{\circ} \mathrm{C}$. \\
\hline $\begin{array}{llll}\text { Right index } \\
\text { Left index }\end{array}$ & $\cdots$ & 15 & 19 & 18 & 21 \\
\hline
\end{tabular}

Experiment 5 : Effect of Ischaemia.-The effects of ischaemia were observed as follows. A sphygmomanometer cuff was placed round the right upper arm and inflated to $200 \mathrm{~mm}$. Hg. The index was then tested and gave a score of 17 on the right. The left index was tested without ischaemia and gave a score of 18 . After the point of failure of the right index had been reached the ischaemia was maintained. In contrast to the non-ischaemic experiments the hardness of the muscle belly and the continued flexion of the index finger did not subside after about one minute but remained unaltered for five minutes when the cuff was released. At another experiment a cuff was placed round the right upper arm and inflated to $200 \mathrm{~mm}$. $\mathrm{Hg}$. The limb was kept at rest and ischaemic paraes- thesiae developed as usual. At the end of 20 minutes' occlusion there was no spontaneous hardening of the muscle. The right "index" was then tested and a reading of 18 was obtained before failure. The cuff was released immediately after the point of failure and the myotonia and weakness disappeared.

These observations on the effect of ischaemia were of great interest. Exercising the muscle during ischaemia did not induce myotonia any more quickly than when a free blood supply was available. However, once the myotonia was induced it did not disappear until the blood supply was restored. Ischaemia in a resting muscle did not induce myotonia, nor did exercise of the muscle after 20 minutes' ischaemia produce more rapid myotonia. These findings suggest that the changes brought about by muscular activity can only be reversed by a free blood supply but that ischaemia, in itself, is insufficient to produce the myotonia, muscular contraction being essential.

Experiment 6 : Effect of Isometric Contraction.The effect of isometric contraction was tried by attaching the loop round the index finger to an immovable weight. The patient then tried to flex the finger as before. In the right hand 30 flexion attempts were made before myotonia developed, and in the left 18. There did not appear to be any difference, therefore, between isotonic and isometric contraction.

Experiment 7 : Effect of Faradic and Galvanic Currents.-Contractions induced by faradic and galvanic currents were observed. The right flexor carpi ulnaris was stimulated by a faradic coil at the rate of 30 contractions per minute. The contractions started strongly, began to fade after 15 , and were a mere flicker at 25 . The normal control was still contracting strongly after 100 contractions. On the left the contraction began to fade at 25 and was a flicker by 40 .

When tested by a 9 milliamp galvanic current produced by a mechanical interrupter at the rate of 30 contractions per minute the flexors carpi ulnaris right and left were still contracting strongly at 60 and 90 respectively. This repeated observation was of considerable interest. The myotonic response to electrical stimulation was not seen, which was in line with the failure of mechanical percussion of the muscle to produce myotonia. Repeated faradic stimulation, however, caused development of myotonia and rapid loss of power. The galvanic stimulation, on the other hand, entirely failed to do this, nor did it, as in two cases of dystrophia myo- 
tonica described by Adie and Greenfield (1923), produce a sustained contraction as long as the current was passing. Faradic current with its short pulses is unable to stimulate muscle fibres directly but acts through the motor nerve. Galvanic current, on the other hand, can stimulate muscle directly. The results of experiment 7 , therefore, might suggest that the myoneural junction was involved in the development of the myotonia. This conclusion, however, is not justifiable, as the faradic current may have resulted in the muscle doing more work than when stimulated by galvanic current. The work done by the muscle under these conditions was unfortunately not tested.

An electromyographic examination was made of the forearm muscles with concentric needle electrodes. Insertion of the needle was followed by a tremendous outburst of electrical activity outlasting movement of the needle by many seconds as described by Brown and Harvey (1939) in congenital myotonia in goats. Voluntary contraction of the muscle was accompanied by action potentials which ceased as the muscle relaxed. With repeated contractions the myotonia gradually developed and was accompanied by the typical after-discharge. These electromyographic findings were very similar to those described by Brown and Harvey (1939).

Experiment 8 : Effect of Potassium Chloride.The serum potassium level of this patient was $17 \cdot 6$ $\mathrm{mg}$. per $100 \mathrm{ml}$. He was given $5 \mathrm{~g}$. of potassium chloride in water to drink, and one hour later the muscle tests were performed (Table V), but there did not appear to be any aggravation of the myotonia. He was later given $45 \mathrm{gr}$. of potassium chloride daily and muscle tests were recorded on the third and twelfth days (Table V), again without any change being apparent.

\section{TABLE V}

EFFECT OF POTASSIUM CHLORIDE, QUININE, AND PROSTIGMINE ON NUMBER OF MUSCULAR CONTRACTIONS REQUIRED TO PRODUCE MYOTONIA

\begin{tabular}{|c|c|c|c|c|c|}
\hline Muscle & $\begin{array}{l}\text { K.Cl. } \\
(5 \text { g. })\end{array}$ & $\begin{array}{l}\text { Third } \\
\text { Day of } \\
45 \text { gr. } \\
\text { K.Cl. } \\
\text { per Day }\end{array}$ & $\begin{array}{l}\text { Twelfth } \\
\text { Day of } \\
45 \text { gr. } \\
\text { K.Cl. } \\
\text { per Day }\end{array}$ & $\begin{array}{l}\text { Fifth } \\
\text { Day of } \\
45 \text { gr. } \\
\text { Quinine } \\
\text { H.Cl. } \\
\text { per Day }\end{array}$ & $\begin{array}{l}\text { Third } \\
\text { Day of } \\
120 \mathrm{mg} \text {. } \\
\text { Prostig- } \\
\text { mine } \\
\text { per Day }\end{array}$ \\
\hline 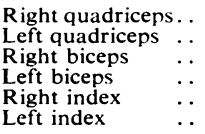 & $\begin{array}{l}- \\
\overline{37} \\
32 \\
13 \\
15\end{array}$ & $\begin{array}{l}31 \\
38 \\
28 \\
30 \\
17 \\
12\end{array}$ & $\begin{array}{l}41 \\
44 \\
31 \\
29 \\
22 \\
21\end{array}$ & $\begin{array}{l}- \\
34 \\
25 \\
18 \\
19\end{array}$ & $\begin{array}{l}\overline{-} \\
36 \\
19 \\
21 \\
21\end{array}$ \\
\hline
\end{tabular}

Experiment 9 : Effect of Quinine Hydrochloride.The patient was given $15 \mathrm{gr}$. of quinine hydrochloride three times a day for four days and on the fifth day the muscle power was tested (Table V), but there was no alleviation of the myotonia in contrast to the relief usually given by quinine in ordinary myotonia.

Experiment 10 : Effects of Prostigmine.-The patient was given $30 \mathrm{mg}$. of prostigmine by mouth every four hours from 6 a.m. to 6 p.m. daily. On the third day of this regime the muscle power was tested (Table V), no change as a result of the prostigmine being observed. Thus, in contrast to the findings of Russell and Stedman (1936) in cases of myotonia congenita, neither potassium chloride nor prostigmine aggravated the myotonia in this case.

Experiment 11 : Effect of Acetyl Choline.-Acetyl choline, $40 \mathrm{mg}$., was injected into the right brachial artery at the elbow (Lanari, 1937). A marked flush and profuse sweating appeared over the hand and forearm with slight weakness of the grip, as is described by Harvey, Lilienthal, and Talbot (1941). The power of flexion of the fingers was then tested simultaneously in both hands against an unknown resistance. Twelve contractions were obtained on the right against 24 on the left, while the degree of myotonia on the right was much more severe than that on the left.

\section{Discussion}

The most noticeable feature of this case was the complete absence of any suggestion of myotonia after the first few contractions. Though the patient was examined on numerous occasions over several weeks never once was myotonia on initial movement or a myotonic response to mechanical stimulation observed. The degree of disability on continued exercise of a muscle, however, was severe.

Opinion has differed as to the site of the lesion in myotonia. Russell and Stedman (1936) considered the lesion to be an excess of acetyl choline at the myoneural junction. Brown and Harvey (1939), who observed congenital myotonia in goats, thought that there was an abnormality of some part of the muscle fibre itself because they found the myotonia to be unaltered after severance and degeneration of the motor nerve and after curare. Denny-Brown and Nevin (1941) believed that there were two factors, a peripheral myotonia due to an abnormality of the muscle fibre, which in turn reflexly stimulated an "after-spasm" due to impulses from the motor nerve. The features of these two types of myotonia were not observed in this case. The observations made on this case have failed to throw much light on the problem of the site of the lesion. 
The failure of quinine hydrochloride, potassium chloride, and prostigmine to influence the myotonia is strong evidence against the myoneural junction being at fault. Nor does the aggravation of the myotonia by acetyl choline contravert this, for, as acetyl choline causes contraction of muscle and the myotonia here developed with muscular contraction, acetyl choline would clearly increase the myotonia. The possibility that the myotonia was central and not peripheral is thus raised. A myotonia of central origin would differ from the " after-spasm" of Denny-Brown and Nevin (1941) in not being dependent on an initial peripheral factor. A central origin of the myotonia could only be proved by denervating or fully curarizing a muscle, which is, unfortunately, not possible.

Comparison of this case with other reports is, however, rendered difficult by the uncertainty as to whether the various forms of myotonia are but variants of the same condition or whether they are separate entities. Maas and Paterson (1939, 1943, 1950) from their extensive clinical and genetic studies believe that all forms of myotonia are manifestations of a unitary disease. Bell (1948) and Franceschetti, Klein, and Walthard (1947), however, oppose this view. The complete failure of potassium and prostigmine to aggravate the myotonia in this case or of quinine to relieve it, suggest fundamental differences from myotonia as seen in myotonia congenita and myotonia atrophica. From the clinical standpoint also so pure a case of myotonia strictly related to continued exertion does not appear to have been described. The possi- bility that the myotonia is in reality a form of muscle cramp seems unlikely in view of the constant, widespread involvement of all muscles, including the tongue and muscles of deglutition. It may well be that this form of myotonia paradoxa is essentially different from ordinary myotonia. Further observations on more cases are required to elucidate the problems which this case has presented.

\section{Summary}

A case of myotonia, entirely related to repeated use of a muscle (myotonia paradoxa) is described, and the results of several observations on the case are reported.

The implications of the observations are discussed.

I wish to thank Dr. W. R. Russell and Dr. C. W. M. Whitty for their help and advice; and Brigadier W. R. D. Hamilton, O.B.E., Director of Medicine, the War Office, for permission to publish.

\section{REFERENCES}

Adie, W. J., and Greenfield, J. G. (1923). Brain, 46, 73. Bell, J. (1948). The Treasury of Human Inheritance, vol. 4, pt 5. London.

Brown, G. L., and Harvey, A. M. (1939). Brain, 62, 341. Denny-Brown, D., and Nevin, S. (1941). Ibid., 64, 1 . Franceschetti, A., Klein, D., and Walthard, K. M. (1947). Schweiz. Arch. Neurol. Psychiat., 60, 48.

Harvey, A. M., Lilienthal, J. L., and Talbot, S. A. (1941). Bull.' Johns Hopk. Hosp., 69, 529.

Lanari, A. (1937). C. R. Soc. Biol.'(Paris), 126, 827.

Maas, O., and Paterson, A. S. (1939). Brain, 62, 198. Maas, (1943). Ibid., 66, 55.

Russell, W. R., and Stedman, E. (1936). Lancet, 2, 742.

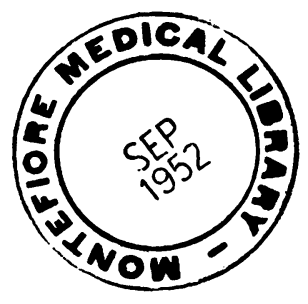

